\title{
Perspectives of healthcare professionals in Nigeria about physiotherapists' scope of practice and skills in ICU patients' management: a cross-sectional study
}

\author{
Nse Odunaiya ${ }^{1}$, Chidile Muonwe ${ }^{2^{*}}$ and Samuel A. Agbaje ${ }^{1}$
}

\begin{abstract}
Background: There is growing evidence for physiotherapy in the intensive care unit (ICU), but physiotherapy in the ICU and patients' referral rate remains low in Nigeria. This study assessed the healthcare professionals' perception of the physiotherapists' scope of practice and skills in managing patients in the ICU of selected teaching hospitals in Southern Nigeria. The study was a cross-sectional survey that involved seventy healthcare professionals working in the ICU who completed an adapted and validated questionnaire. The data obtained from the cross-sectional study were presented using descriptive statistics of mean, standard deviation, frequency distribution, and percentage.

Results: The mean age of the participants was $39.74 \pm 7.08$ years. The majority of the participants had a bachelor's degree and had worked for a minimum of 5 years in the ICU, with all the participants working in a mixed ICU and 46.7\% work in ICUs with four to six beds. Physiotherapists (PTs) are not posted exclusively to the ICUs, and PTs were reported to be on call in most of the ICUs during the weekdays and weekends. Patients were referred for physiotherapy by the physicians. Healthcare professionals had negative perceptions about PTs'scope in airway suctioning, nebulization, weaning, and adjustment of mechanical ventilators, intubation, extubation, and changing tracheostomy tubes for ICU patients. Participants had a positive perception about PTs' assessment skills in the ICU except for hypoxemia calculation, readiness for weaning, and the need for humidification.
\end{abstract}

Conclusion: Healthcare professionals working in the ICU in the selected hospitals had both negative and positive perceptions regarding certain areas about the scope of practice and skills of PTs in managing patients in the ICU.

Keywords: Physiotherapy practice scope, Intensive care unit, Physiotherapists' role, Healthcare professionals' perception

\section{Introduction}

Adequate care of patients admitted in the ICU requires the contributions of ideas and skills from varied healthcare professionals that form an interdisciplinary team. Collaboration from inter-professional healthcare

\footnotetext{
*Correspondence: cs.muonwe@unizik.edu.ng; samuelchidile@gmail.com ${ }^{2}$ Department of Medical Rehabilitation, College of Health Sciences and Technology, Nnamdi Azikiwe University, Nnewi Campus, Awka, Nigeria

Full list of author information is available at the end of the article
}

providers promotes positive outcomes of care. This collaboration may include regular interaction between professionals, recognizing the unique contributions of different disciplines, and valuing professionals' expertise [1]. This collaboration is strengthened by the ability of each professional that forms the multi-team to know and understand the roles that each discipline plays in the patient care continuum and the common task and goals of the team for each patient [2]. The recognition of equality in expressing views and contributions towards a patient's care without fear of criticism by each 
professional is a crucial characteristic of an effective team [3]. In the ICU, contributions from physicians and other healthcare providers, including physiotherapists (PTs), are pivotal to patients' recovery.

Physiotherapy is part of the primary services provided in the ICU [4] and its scope of practice includes respiratory management and rehabilitation [5]. PTs carry out an individualized assessment of patients admitted to the ICU to identify the needs of each patient $[5,6]$. The role of the PTs is pivotal in the prevention and management of respiratory, cardiovascular, musculoskeletal, and neuromuscular disorders in both intubated and spontaneously breathing patients in the ICU [5, 7-9].

Evidence has shown that physiotherapy for critically ill patients admitted to ICU is safe, feasible, and effective [10-13]. Physiotherapy was shown to prevent ventilatorassociated pneumonia [14], improve pulmonary function $[5,12]$, improve respiratory muscle strength $[15,16]$, aid patient weaning off the mechanical ventilator $[5,15,17]$, reduce ventilator length of stay [16], and the overall hospitalization costs [18].

Despite the growing evidence for physiotherapy in the ICU, patients' referral rate remains low, especially in developing countries like Nigeria [19]. Yeole et al. [20] observed that factors such as the attitude of the referring physicians and other team members towards physiotherapy in the management of patients in the ICU, the training and qualification of PTs, and the expertise and skills possessed by the PTs could affect the utilization of physiotherapy in ICU. This study investigated the perceptions of PTs' scope of practice and skills in the management of patients in ICU among referring physicians and other ICU team members in Southern Nigeria.

\section{Methods}

\section{Study design}

The study was a questionnaire-based cross-sectional survey.

\section{Study population}

The study population comprised of healthcare professionals (physicians and nurses) who have worked in the ICU for the past 12 months and gave their consent to participate.

\section{Sampling technique and sample size}

The purposive sampling technique was used to select the teaching hospitals, and convenient sampling was used to recruit participants to the study. The sample size for this study included all consenting healthcare professional (HCP) who met the criteria for inclusion.

\section{Procedure for data collection}

Ethical approval was sought and obtained from the Health Research Ethics Committee of the University of Ibadan/University College Hospital Ibadan (UI/UCH) before the commencement of the study (NHREC/05/01/2008a). The purpose of the study was explained to the participants, and their informed consent was sought and obtained. Quantitative data was collected using an adapted questionnaire from the questionnaire developed by Van Aswegen and Potterton [21]. The instrument was modified to assess the perception of the scope of practice of PTs and skills in managing patients in the ICU by other HCPs in the ICU team. The standard protocol for questionnaire adaptation was observed before the questionnaire was modified. Copies of the questionnaire were distributed to and collected from the participants by hand in one of the hospitals and through contact persons in other hospitals.

\section{Questionnaire description}

A 37-item questionnaire developed by Van Aswegen and Potterton [21] to assess the scope of physiotherapy practice in South African ICUs was identified as relevant to the present study. The questionnaire was modified and adapted for use in Nigeria setting.

\section{Process of adaptation}

Permission was sought and obtained from the developer of the question before it was modified and adapted. Questions were modified and some excluded (question 1 on provinces was removed; question 3 on type of hospital was removed because all the hospitals included were the same; in question 6 , mixed type of ICU was included as an option; questions 4, 8, 15, 19, and 21 also were excluded; questions 23 and 24 were modified accordingly) to suit the Nigerian context. The language was modified to suit contextual usage. An expert panel meeting comprising three experts was held at the physiotherapy department, college of medicine, and Ibadan to validate the items selected from the questionnaire. A draft version of the modified questionnaire was produced after the expert panel meeting. The draft version of the modified questionnaire was pre-tested among ICU physicians and nurses who are involved in the management of patients in the ICU in one of the teaching hospitals in South-Western Nigeria. This was done to ascertain the clarity and comprehension of the questions among the target population. After the pre-test, an expert panel meeting was held to consider the result of the pre-test. Result of the pre-test: Four anesthetists noted that Bachelor of Medicine, Bachelor of Surgery (MBBS) should be included as an option in question three, two anesthetists 
also noted that fellowship should be included as an option in question three, and two nurses noted that Registered Nurse (RN) should be included as an option in question three. Six participants suggested that "Not Sure" should be included as an option in questions 9, 10, and 11. At the end of the expert panel meeting, a final version of the questionnaire comprising of three sections and 35 items was produced. Section one collected information on socio-demographic characteristics of participants, section two obtained information on the perceptions of HCP on PTs assessment skills, while section three obtained information on HCP perceptions on PTs treatment skills.

\section{Data analysis}

Data were analyzed using Statistical Package of Social Science (SPSS) version 20.0 and summarized using descriptive statistics of mean, standard deviation, frequency counts, and percentages.

\section{Results}

Seventy healthcare professionals completed the survey. The mean age of the participants was $39.74 \pm 7.08$ years. $64.3 \%$ of the participants have a bachelor's degree. The HCPs involved in this study consisted of nurses (50\%), anesthetists (45.7\%), and neurologists (4.3\%). More than half $(67.1 \%)$ of participants had 5 years or less experience working in the ICU, while about $33.9 \%$ have more than 5 years of experience working in the ICU (Table 1). Mixed-type ICU existed in all the centers. The number of beds in the two hospitals is more than 10 , while the other centers had four to 10 bedded ICUs. Most ICUs (46.9\%) had at least 4 to 6 beds actively in use per month. None of the ICUs had PTs working exclusively in it. Regarding patient referrals, $97.1 \%$ of respondents noted that

Table 1 Demographical characteristics of the participants

\begin{tabular}{llll}
\hline Variable & Category & Frequency & Percentage (\%) \\
\hline Gender & Men & 23 & 32.9 \\
& Women & 47 & 67.1 \\
Education & RN & 8 & 11.4 \\
& Bachelor/MBBS & 45 & 64.3 \\
& MSc & 9 & 12.7 \\
& PGD & 5 & 7.1 \\
Profession & Fellowship & 3 & 4.3 \\
& Anesthetists & 32 & 45.7 \\
& Nurse & 35 & 50 \\
Years of practice & $1-5$ & 3 & 4.3 \\
& Neurologist & 47 & 67.14 \\
& $>10$ & 17 & 24.28 \\
& & 6 & 8.57 \\
\hline
\end{tabular}

patients' referrals are done only to physicians. PTs are on call on both weekdays (68.8\%) and weekends (86.5\%), and most of the PTs stay within the hospital during call hours (Table 2).

More than half of the participants $(62.9 \%)$ perceived PTs to be trained to review ICU charts as part of the patient assessment process. Greater percentage of the participants had a positive perception about PTs' skills in assessing the arterial blood gas status of the patients (55.7\%) and dynamic and static lung compliance (50\%). The majority of the participants had a negative perception about the PTs' skills in assessing hypoxemia (57.1\%),

Table 2 ICU demographical characteristics

\begin{tabular}{|c|c|c|c|}
\hline Variable & \multicolumn{3}{|l|}{$\mathrm{TOP}=70$} \\
\hline Type of ICU & Mixed & 70 & 100 \\
\hline \multirow[t]{4}{*}{ Number of ICU beds } & $<4$ & 1 & 1.4 \\
\hline & $4-6$ & 40 & 57.1 \\
\hline & $7-10$ & 17 & 24.3 \\
\hline & $>10$ & 12 & 17.1 \\
\hline \multirow[t]{4}{*}{ Active beds } & $4-6$ & 50 & 71.4 \\
\hline & $7-8$ & 9 & 12.9 \\
\hline & $9-12$ & 8 & 11.4 \\
\hline & $13-18$ & 3 & 4.3 \\
\hline \multirow[t]{5}{*}{ Number of ICU/ward PTs } & $1-2$ & 4 & 5.7 \\
\hline & $3-4$ & 12 & 17.1 \\
\hline & $>4$ & 11 & 15.7 \\
\hline & All & 9 & 12.9 \\
\hline & Not sure & 34 & 48.6 \\
\hline \multirow[t]{3}{*}{ Exclusive ICU PTs } & Yes & 5 & 7.1 \\
\hline & No & 55 & 78.6 \\
\hline & Not sure & 10 & 14.3 \\
\hline \multirow[t]{4}{*}{ No. of exclusive ICU PTs } & None & 60 & 85.7 \\
\hline & $3-4$ & 3 & 4.3 \\
\hline & $>4$ & 2 & 2.9 \\
\hline & Not sure & 5 & 7.1 \\
\hline \multirow[t]{2}{*}{ Patient referral } & Physicians & 68 & 97.1 \\
\hline & Nurse & 2 & 2.9 \\
\hline \multirow[t]{2}{*}{ PT weekday calls } & Yes & 49 & 70 \\
\hline & No & 21 & 30 \\
\hline \multirow[t]{2}{*}{ PT weekend calls } & Yes & 62 & 88.6 \\
\hline & No & 8 & 11.4 \\
\hline \multirow{3}{*}{$\begin{array}{l}\text { PTs available during call } \\
\text { hours }\end{array}$} & None & 8 & 11.4 \\
\hline & Yes & 47 & 67.1 \\
\hline & No & 15 & 21.4 \\
\hline \multirow{3}{*}{$\begin{array}{l}\text { Patient referral during } \\
\text { calls }\end{array}$} & Medical officer & 25 & 35.7 \\
\hline & Registrar & 15 & 21.4 \\
\hline & Consultant & 30 & 42.9 \\
\hline
\end{tabular}

PT physiotherapist, ICU intensive care unit, No. number, TOP total number of participants 
patient readiness for weaning (54.3\%), and patients' need for nebulization (57.1\%). Further details can be found in Table 3.

Greater percentage of the participants had a positive perception about PTs' scope of practice in the use of manual chest clearance technique to treat patients in the ICU (87.1\%) and the use of postural drainage in patient management in the ICU 57.1\%. Also, participants had a negative perception about PTs' scope of practice in airway suction $65.7 \%$, manual hyperinflation $58.6 \%$, intermittent positive pressure breathing $52.9 \%$, and the blow of bottle 58.6\%. Further details can be found in Table 4 .

The participants were also asked questions about PTs' involvement in ICU team activities. ICU team rounds are held in most of the ICUs. Majority (90\%) of the participants noted that PTs do not participate in the ICU team rounds in their ICUs. PTs do not participate in morbidity and mortality meetings held in the majority of the ICUs. PTs do not present seminars in most of the ICUs. As shown in Table 5.

\section{Discussion}

This study explored the perception of HCPs working in the ICU of the selected teaching hospitals in Southern Nigeria about PTs' scope of practice and skill in managing patients in the ICU. This study showed that there were more nurses than other HCPs who completed the survey. There are more nurses than other HCPs

Table 3 Perception of HCPs about PTs' assessment skills

\begin{tabular}{lll}
\hline Skill & $\mathbf{P P}^{\mathbf{a}}$ & $\mathbf{N P}^{\mathbf{b}}$ \\
& $\mathbf{N}(\%)$ & $\mathbf{N}(\%)$ \\
& TOP $=\mathbf{7 0}$ & \\
\hline ICU chart review & $44(62.9)$ & $26(37.1)$ \\
Arterial blood analysis & $39(55.7)$ & $31(44.3)$ \\
DSLCC & $35(50.0)$ & $35(50.0)$ \\
Hypoxemia calculation & $30(42.9)$ & $40(57.1)$ \\
X-ray/CT scan & $51(72.1)$ & $19(27.1)$ \\
Auscultation & $50(71.4)$ & $20(28.6)$ \\
Strength of cough & $58(82.9)$ & $12(17.1)$ \\
Thoracic expansion & $56(80.0)$ & $14(20.0)$ \\
Percussion note & $47(67.1)$ & $23(32.9)$ \\
Respiratory muscle training & $55(78.6)$ & $15(21.4)$ \\
Readiness for weaning & $32(45.7)$ & $38(54.3)$ \\
Readiness for mobilization & $50(71.4)$ & $20(28.6)$ \\
Peripheral muscle training & $37(52.7)$ & $33(47.3)$ \\
Need for humidification & $30(42.9)$ & $40(57.1)$
\end{tabular}

TOP total number of participants, ICU intensive care unit, DSLCC dynamic and static lung compliance calculation

${ }^{\text {a }}$ Positive perception

${ }^{\mathrm{b}}$ Negative perception
Table 4 Perception of HCPs about PTs' treatment skills

\begin{tabular}{|c|c|c|}
\hline Technique & $\begin{array}{l}\mathrm{PP}^{\mathrm{a}} \\
N(\%) \\
\text { TOP }=70\end{array}$ & $\begin{array}{l}\mathrm{NP}^{\mathrm{b}} \\
N(\%)\end{array}$ \\
\hline МСCT & $61(87.1)$ & $9(12.9)$ \\
\hline Postural drainage & $40(57.1)$ & $30(42.9)$ \\
\hline Airway suctioning & $24(34.3)$ & $46(65.7)$ \\
\hline Manual hyperinflation & $29(41.4)$ & $41(58.6)$ \\
\hline IPPB & $33(47.1)$ & $37(52.9)$ \\
\hline Incentive spirometry & $41(58.6)$ & $29(41.4)$ \\
\hline ACBT & $44(62.9)$ & $26(37.1)$ \\
\hline IMT & $42(60.0)$ & $28(40.0)$ \\
\hline Flutter device & $36(51.4)$ & $34(48.6)$ \\
\hline Blowing of bottle & 29(41.4) & $41(58.6)$ \\
\hline Blowing of glove & $45(64.3)$ & 25(35.7) \\
\hline Deep breathing exercise & $46(64.7)$ & $24(35.3)$ \\
\hline Nebulization & $36(51.4)$ & $34(48.6)$ \\
\hline Mobilization in bed & $48(68.6)$ & $22(31.4)$ \\
\hline Mobilization out of bed & $53(75.7)$ & $17(24.3)$ \\
\hline Positioning in bed & $53(75.7)$ & $17(24.3)$ \\
\hline Positioning out of bed & $53(75.7)$ & $17(24.3)$ \\
\hline PMSE & 65(92.9) & $5(7.1)$ \\
\hline AMV & $15(21.4)$ & $55(78.6)$ \\
\hline AIWMV & $5(7.1)$ & $65(92.9)$ \\
\hline ISNIVS & $4(5.7)$ & $66(93.3)$ \\
\hline Intubation of patients & $0(0.0)$ & $70(100)$ \\
\hline Extubation of patients & $0(0.0)$ & $70(100)$ \\
\hline CTT & $0(0.0)$ & $70(100)$ \\
\hline
\end{tabular}

TOP total number of participants, MCCT manual chest clearance techniques, IPPB intermittent positive pressure breathing, $A C B T$ active cycle of breathing, IMT inspiratory muscle training, PMSE peripheral muscle strengthening exercises, $A M V$ adjustment of mechanical ventilator settings, AIWMV active involvement in weaning off mechanical ventilator, ISNIV implementation and supervision of non-invasive ventilatory support, CTT change of tracheostomy tube

${ }^{\text {a }}$ Positive perception

${ }^{\mathrm{b}}$ Negative perception

because more nurses are needed for nursing in ICU, nurse to patient ratio is expected to be $1: 1$; therefore, more nurses are usually employed than other HCPs [22, 23]. Most of the participants in this study had bachelor's degrees and had 5 years or less experience working in the ICU. All the participants in this study work in a mixed-type of ICU, with the majority of the ICUs where the participants in this study work being 4-6 bedded and mainly occupied through the month. In Nigeria, only mixed ICUs are available because critical care is still evolving and has not yet attained specialized ICUs status.

PTs are not posted exclusively to work in the ICU as reported by most participants in this study which contradicts previous studies $[5,21,24,25]$. This may be 
Table 5 PTs involvement in ICU team as reported by other HCPS

\begin{tabular}{llll}
\hline Variables & & Frequency & Percentage (\%) \\
\hline Are there ICU team rounds in your ICU? & Yes & 46 & 65.7 \\
& No & 24 & 34.3 \\
Are PTs part of ICU team rounds? & Yes & 7 & 10 \\
& No & 63 & 90 \\
How often are the ICU team rounds? & Daily & 63 & 1.4 \\
& Weekly & 6 & 90 \\
Are PTs part of morbidity and mortality meetings? & Monthly & 1 & 14.3 \\
& Yes & 10 & 85.7 \\
Do PTs present seminars? & No & 60 & 18.6 \\
& Yes & 13 & 81.4
\end{tabular}

PT physiotherapists

because critical care is still evolving, and specialization among PTs in Nigeria is also evolving. Also, this could be a result of the professional disharmony in Nigeria's healthcare system, which has made the multidisciplinary team approach in patient care almost impossible [26]. Posting of PTs to ICU is practiced in developed countries where specialization in critical care among PTs has been established, and teamwork and collaborative practice are the norm in patient management. We also found that patients' management by PTs in the ICU is solely dependent on physicians' referral which is in line with Lottering and Aswagen [27] and Sigera et al. [28]. It is important to note that physiotherapy interventions may be underutilized if the referring physician is not knowledgeable or has a negative perception of physiotherapists' skill and scope of practice in managing patients in ICU [29]. The cases reported by Lottering and Aswagen [27] and Sigera et al. [28] may not be exactly like the case in Nigeria in the sense that though physiotherapy work on referral in ICU in those places, physiotherapy was not underutilized like observed in Nigeria [19]. The difference in utilization level lies in knowledge and perception of role, the scope of practice, and the skill of PTs by referring physicians. Also, in the present study, we found that PTs work during call hours during the weekday and the weekends. This is impressive as PTs can always see the patients several times a day as recommended by various clinical trials of physiotherapy in ICU care [30-32]. From this study, the scope of PTs' practice was generally perceived to comprise both respiratory management and mobilization. This finding is consistent with that of previous studies in Europe, Greece, India, and South Africa [5, $21,24,25,33]$. However, as seen in other countries, mainly developed countries, specific roles of PTs were perceived negatively by other HCPs in this study. These specific roles and skills were airway suctioning, manual hyperinflation, involvement in weaning, and implementation of non-invasive ventilation. This difference could be due to the poor interprofessional education in Nigeria. Participants in the present study saw the review of patients' charts in the ICU as part of the assessment skill that PTs possessed, which corroborated previous studies $[5,25]$..

The findings from this study show that PTs do not attend ICU team rounds. Also, they do not take part in teaching other HCPs in the ICU. This further points out the lack of teamwork for many reasons which were not explored in this study. Overall, the findings from this study contradict that of Lottering and Aswegen [27], where PTs were involved in ICU team rounds at least once a day. The difference in the present and previous studies could also be attributed to poor interprofessional education and teamwork among Nigeria's HCPs. This has been reported in other studies in Nigeria [34, 35], which may reflect the failing health system in Nigeria.

\section{Conclusion and recommendation}

HCPs working in the ICU in the selected hospitals had a mixed perception about the PTs' scope of practice and skills in managing patients in the ICU. There was an overall negative perception about PTs' involvement with nebulization, intubation, extubation, and implementation of weaning and supervision of non-invasive ventilation, adjustment of ventilator setting for patients in the ICU. Factors predicting these perceptions need to be explored in another study to proffer a solution to the poor referral rate and underutilization of physiotherapy in Nigerian ICUs. This also calls for the need for interprofessional education among ICU team members and emphasis on 
adopting a multidisciplinary approach in the patient care in the Nigeria ICU and the ICUs of other countries where similar challenges may exist.

\section{Abbreviations}

ICU: Intensive care unit; PTs: Physiotherapists; HCP: Healthcare professionals; MBBS: Bachelor of Medicine, Bachelor of Surgery.

\section{Supplementary Information}

The online version contains supplementary material available at https://doi. org/10.1186/s43161-021-00066-4.

Additional file 1. Questionnaire to explore healthcare professionals' perception of physiotherapist scope of practice and skills in the management of patients admitted to the Intensive Care Unit.

\section{Acknowledgments}

We appreciate all the participants in this study for sparing their time to complete the questionnaire.

\section{Authors' contributions}

$\mathrm{NO}$ and $\mathrm{MC}$ were responsible for the conceptualization/design; $\mathrm{MC}$ and $\mathrm{AS}$ did acquisition and analysis; NO did interpretation of data; MC and NO were responsible for drafting and revision. The authors read and approved the manuscript.

\section{Funding}

No form of funding was received for this study

\section{Availability of data and materials}

The datasets used and/or analyzed during the current study are available from the corresponding author on reasonable request.

\section{Declarations}

\section{Consent for publication}

Not applicable

\section{Competing interests}

The authors declare that they have no competing interest.

\section{Author details}

${ }^{1}$ Department of Physiotherapy, College of Medicine, University of Ibadan, Ibadan, Nigeria. ${ }^{2}$ Department of Medical Rehabilitation, College of Health Sciences and Technology, Nnamdi Azikiwe University, Nnewi Campus, Awka, Nigeria.

Received: 4 November 2021 Accepted: 8 December 2021

Published online: 28 February 2022

\section{References}

1. Reeves S, Pelone F, Harrison R, Goldman J, Zwarenstein M. Interprofessional collaboration to improve professional practice and healthcare outcomes. Cochrane Database Sys Rev. 2017;6(6):CD000072.

2. Tan TC, Zhou H, Kelly M. Nurse-physician communication - an integrated review. J Clin Nurs. 2017;26(23-24):3974-89.

3. Frankel A, Haraden C, Frederico F, Lenoci-Edwards J. A framework for safe, reliable, and effektive care. White Paper. Cambridge, MA: Institute for Healthcare Improvement and Safe \& Reliable Healthcare; 2017.

4. Brown C and Bolton S. Critical care services: physiotherapy. Guidelines for Provision of Intensive care. 2015; 34-35.

5. Gosselink R, Clerckx B, Robbeets C, Vanhullebusch T, Vanpee G, Segers J. Physiotherapy in the intensive care unit. Neth J Crit Care. 2011;15:66-75.
6. Grill E, Quittan M, Huber EO, Boldt C, Stucki G. Identification of relevant ICF categories by health professionals in the acute hospital. Disabil Rehabil. 2005:27:437-45.

7. Schweickert WD, Pohlman MC, Pohlman AS, Nigos C, Pawlik AJ, Esbrook $\mathrm{CL}$, et al. Early physical and occupational therapy in mechanically ventilated, critically ill patients: a randomised controlled trial. Lancet. 2009:73:1874-82

8. Berney SC, Harrold M, Webb S, Seppelt IM, Patman S, Thomas PJ, et al. Intensive care unit mobility practices in Australia and New Zealand: a point prevalence study. Crit Care Resusc. 2013;15:260-5.

9. Nydahl P, Ruhl AP, Bartoszek G, Dubb R, Filipovic S, Flohr HJ, et al. Early mobilization of mechanically ventilated patients: a 1-day point-prevalence study in Germany. Crit Care Med. 2004;42:1178-86.

10. Nordon-Craft A, Moss M, Quan D, Schenkman M. Intensive care unitacquired weakness: implications for physical therapist management. Phys Ther. 2012;92:1494-506.

11. Berney S, Haines K, Denehy L. Physiotherapy in critical care in Australia. Cardiopulmonary Phys Ther. 2012;23:19-25.

12. Stiller K. Physiotherapy in intensive care: an updated systematic review. Chest. 2013:144:825-47.

13. Hodgson CL, Berney S, Harrold M, Saxena M, Bellomo R. Clinical review: early patient mobilization in the ICU. Crit Care. 2013;17:207-13.

14. Ntoumenopoulos G, Presneill JJ, McElholum M, Cade JF. Chest physiotherapy for the prevention of ventilator associated pneumonia. Intensive Care Med. 2002;28:850-6.

15. Elkins $M$, Dentice R. Inspiratory muscle training facilitates weaning from mechanical ventilation among patients in the intensive care unit: a systematic review. J Physiother. 2015;61:125-34.

16. Kayambu G, Boots R, Paratz J. Physical therapy for the critically ill in the ICU: a systematic review and meta-analysis. Crit Care Med. 2013:41:1543-54.

17. Martin AD, Davenport PD, Franceschi AC, Harman E. Use of inspiratory muscle strength training to facilitate ventilator weaning: a series of 10 consecutive patients. Chest. 2002;122:192-6.

18. Needham DM. Mobilizing patients in the intensive care unit: improving neuromuscular weakness and physical function. JAMA. 2008;300:1685-90.

19. Akinremi A, Akinkuade K. Admission pattern, referral rate and scope of physiotherapy services in a Nigerian intensive care unit. Eur Respir J. 2015:46:37-1.

20. Yeole UL, Chand AR, Nandi BB, Gawali PP, Adkitte RG. Physiotherapy practices in intensive care units across Maharashtra. Indian J Crit Care Med. 2015;19:669-73.

21. Van Aswegen $\mathrm{H}$, Potterton J. A pilot survey of the current scope of practice of South African physiotherapists in intensive care units. S Afr J Physiother. 2005;61:17-21.

22. Chamberlain D, Pollock W, Fulbrook P. ACCCN workforce standards for intensive care nursing: systematic and evidence review, development, and appraisal. Aust Crit Care. 2018:31:292-302.

23. British Association of Critical Care Nursing (BACCN). Position statement. Nurse-patient ratios in critical care. Nurs Crit Care. 2001;6:59-63.

24. Kumar JA, Maiya AG, Pereira D. Role of physiotherapists in intensive care units of India: a multicenter survey. Indian J Crit Care Med. 2007; 11:198-203

25. Grammatopoulou E, Charmpas N, Strati G, Nikolaos T, Evagelodimou A, Belimpasaki $V$, et al. The scope of physiotherapy services provided in public ICUs in Greece: a pilot study. Physiother Theory Pract. 2017;33:138-46.

26. Adeloye D, Rotimi AD, Adenike AO, Asa A, Adedape A, Mukhtar G, et al. Health workforce and governance: the crisis in Nigeria. Hum Resour Health. 2017:15:32

27. Lottering M, Van Aswegen H. Physiotherapy practice in South African intensive care units. S Afr J Crit Care. 2016:32:11-6.

28. Sigera PC, Tunpattu TM, Jayashantha TP, De Silva AP, Athapattu PL, Dondorp A, et al. National profile of physical therapists in critical care units of Sri Lanka: lower middle-income country. Phys Ther. 2016;9(7):933-9. https://doi.org/10.2522/ptj.20150363.

29. Alshehri MA, Alhasan H, Alayat M, Al-Subahi M, Yaseen $K$, Ismail A, et al. Factors affecting the extent of utilization of physiotherapy services by physicians in Saudi Arabia. J Phys Ther Sci. 2018;30(2):216-22. https://doi. org/10.1589/jpts.30.216 
30. Morris P, Goad A, Thompson C, Taylor K, Harry B, Passmore L, et al. Early intensive care unit mobility therapy in the treatment of acute respiratory failure. Crit Care Med. 2008;36:2238-43.

31. Sommers J, Engelbert RH, Dettling-Ihnenfeldt D, Gosselink R, Spronk P, Nollet $F$, et al. Physiotherapy in the intensive care unit: an evidence-based, expert driven, practical statement and rehabilitation recommendations. Clin Rehabil. 2015;3:1-13.

32. Kress JP. Clinical trials of early mobilization of critically ill patients. Crit Care Med. 2009:37:442-7.

33. Norrenberg M, Vincent JL. A profile of European intensive care unit physiotherapists. Intensive Care Med. 2000;26:850-6.

34. Onyekwere LA. Inter-professional collaboration and work efficiency in secondary healthcare delivery system in Rivers State. Int J Sci Res Edu. 2013;6:9-46.

35. Erhabor $\mathrm{O}$, Adias T. Harmony in the health sector: a requirement for effective healthcare delivery in Nigeria. Asian Pac J Trop Biomed. 2014;7645:60196

\section{Publisher's Note}

Springer Nature remains neutral with regard to jurisdictional claims in published maps and institutional affiliations.

\section{Submit your manuscript to a SpringerOpen ${ }^{\odot}$ journal and benefit from:}

- Convenient online submission

- Rigorous peer review

- Open access: articles freely available online

- High visibility within the field

- Retaining the copyright to your article

Submit your next manuscript at $\mathbf{s p r i n g e r o p e n . c o m ~}$ 